\title{
ADVANCED SOLAR CELL AND ARRAY TECHNOLOGY FOR NASA DEEP SPACE MISSIONS
}

\author{
Michael F. Piszczor, Scott W. Benson, David A. Scheiman*, Homer J. Fincannon, \\ Steven R. Oleson and Geoffrey A. Landis \\ NASA John Glenn Research Center, \\ * ASRC Aerospace Corporation
}

\section{ABSTRACT}

A recent study by the NASA Glenn Research Center assessed the feasibility of using photovoltaics (PV) to power spacecraft for outer planetary, deep space missions. While the majority of spacecraft have relied on photovoltaics for primary power, the drastic reduction in solar intensity as the spacecraft moves farther from the sun has either limited the power available (severely curtailing scientific operations) or necessitated the use of nuclear systems. A desire by NASA and the scientific community to explore various bodies in the outer solar system and conduct "longterm" operations using smaller, "lower-cost" spacecraft has renewed interest in exploring the feasibility of using photovoltaics for missions to Jupiter, Saturn and beyond. With recent advances in solar cell performance and continuing development in lightweight, high power solar array technology, the study determined that photovoltaics is indeed a viable option for many of these missions. 


\section{Advanced Solar Cell and Array Technology for NASA Deep Space Missions}

Presented at the 33rd Photovoltaic Specialists Conference May 16, 2008

Michael Piszczor, Scott Benson, David Scheiman*, Homer Fincannon, Steve Oleson \& Geoffrey Landis NASA Glenn Research Center 


\section{Background \& Outline}

- Alan Stern request: “...a quick look study for how we could extend the Juno and Rosetta 5 AU-class missions on solar arrays to enable solar array missions at Saturn (10 AU) and Uranus (20 AU)"

- Cell and Array Technology Findings

- Mission and System Integration Studies

- Technology Development Impacts

- Conclusions 


\section{Most Distant Use of Solar Arrays}

- Dawn

- $36.4 m^{2}$ planar array area

- $10.3 \mathrm{~kW}$ at $1 \mathrm{AU}$

- $1.3 \mathrm{~kW}$ at $3 \mathrm{AU}\left(-88{ }^{\circ} \mathrm{C}\right)$

- Triple Junction cells

- Juno

- PDR design

- $55 \mathrm{~m}^{2}$ planar array area

- Equiv. 16.3 kW BOL at $1 \mathrm{AU}$

- $425 W$ EOL at $5.5 \mathrm{AU}\left(-130^{\circ} \mathrm{C}\right)$

- Triple Junction cells

- Rosetta

- $61.5 m^{2}$ planar array area

- $7.1 \mathrm{~kW} \mathrm{BOL}$ at $1 \mathrm{AU}$

$-400 \mathrm{~W}$ at $5.25 \mathrm{AU}\left(-130^{\circ} \mathrm{C}\right)$

- Silicon cells

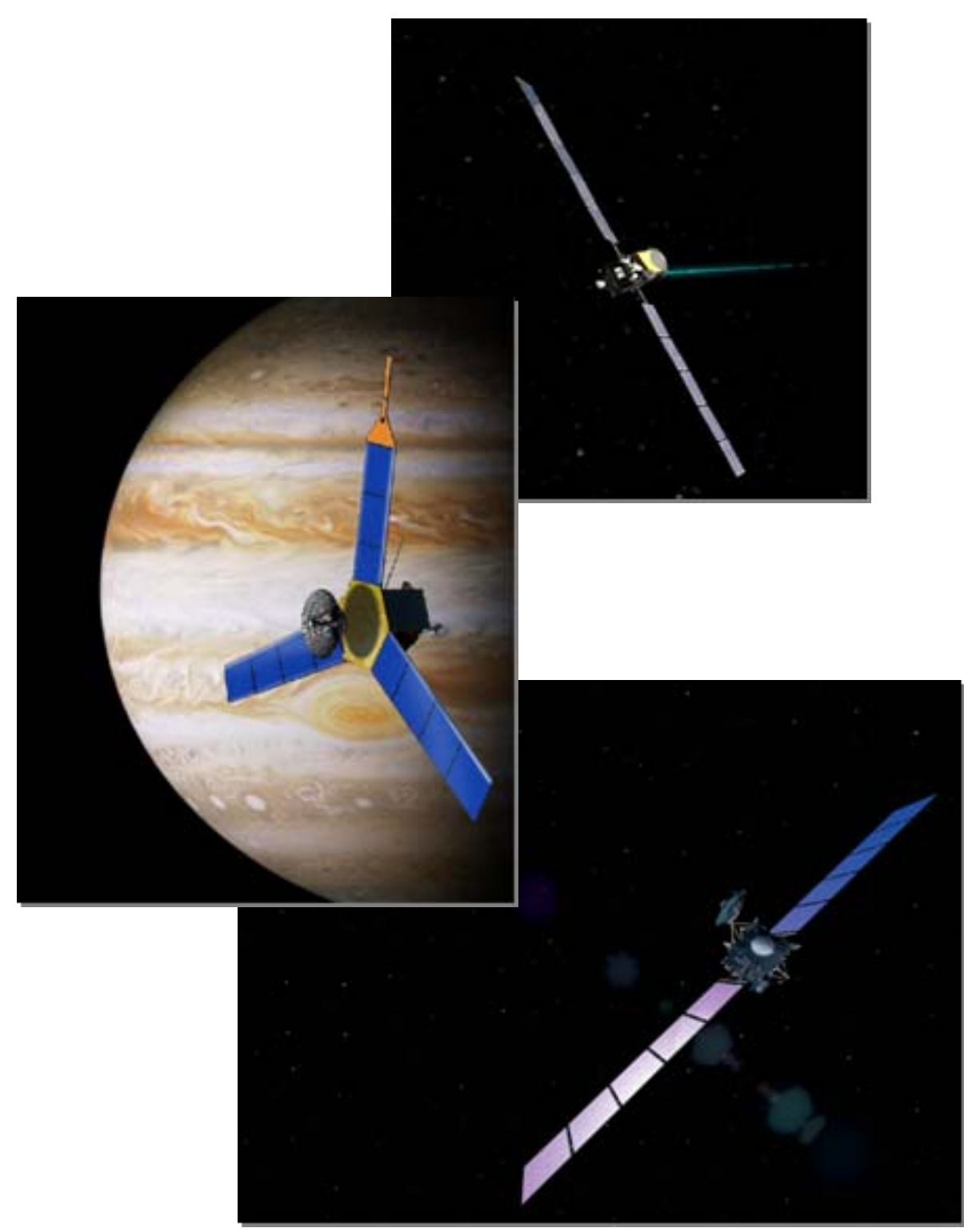




\section{Applicable Technologies - Solar Cells}

\section{- State-of-art performance at 1AU (AM0, 25C)}

- Multi-junction III-V cells, triple-junction: 28 - 30\%

- Silicon: 16 - 19\%

- Thin-film: not space-qualified (6 - 10\% currently)

- Expected advances in cell performance

- Multi-junction: 30 - 33\% in next 3 years

- Development pursued by both cell vendors

- Driven by military/commercial applications

- 35 - 40\% cell design under development

- Multi-junction: mass and cost reduction

- Thinned substrate or no-substrate technology to drastically reduce cell/array mass

- Reusable substrates and improved manufacturing to increase yield and reduce cost

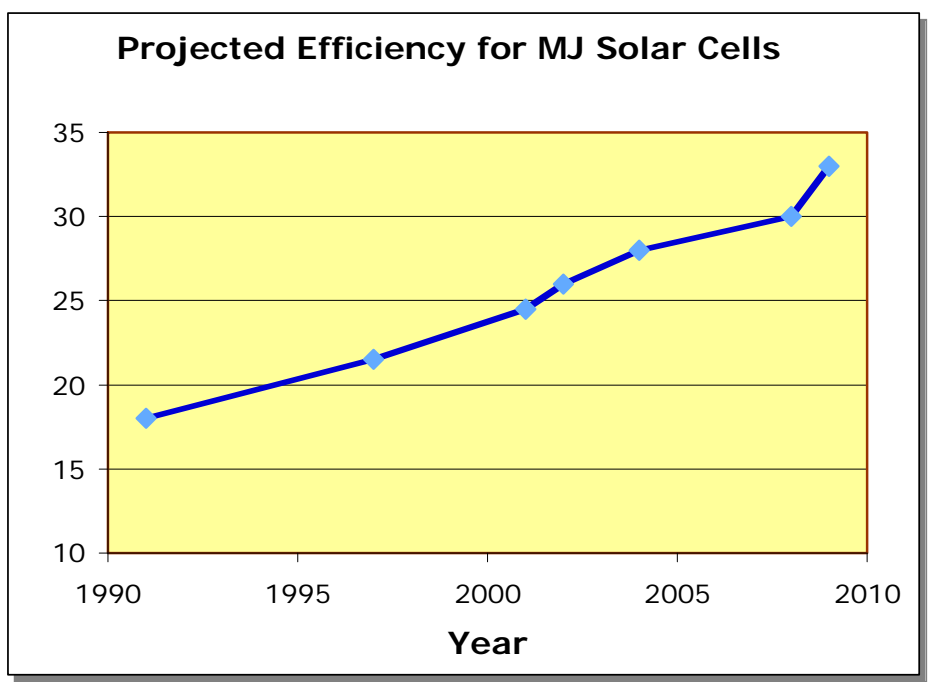

\section{- Advanced cell approaches}

- Cells designed or optimized for outer solar system missions

- Eliminate LILT Effect in future MJ cell generations

- Optimize cells for bandgap narrowing at low temperatures

- Quantum dots, nanotechnology to increase efficiency

- Far-term: efficiency increase through better utilization of solar spectrum 


\section{Solar Cell Technology Findings}

\section{Solar Cell Capability}

- Nominal low intensity, low temperature (LILT) state-of-the-art (SOA) cell performance is viable at $5 \mathrm{AU}$ and beyond

- Cell efficiency increases with lower temperature but decreases with lower intensity

- LILT Effect: off-nominal drop in cell performance, must be mitigated to effectively use solar power in outer

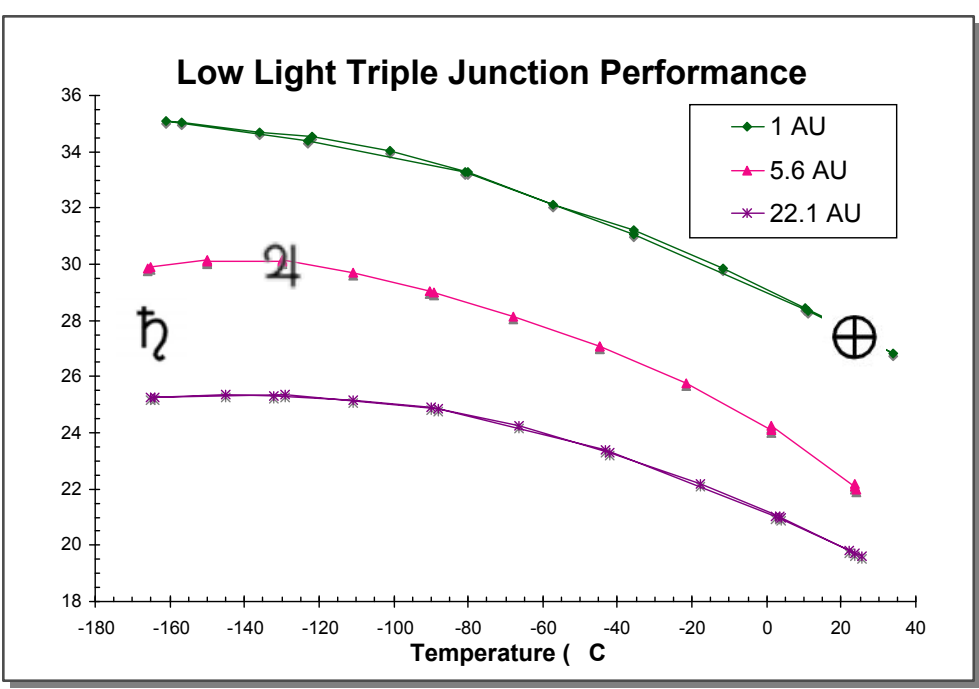

GRC FY07 LILT IRAD testing results solar system

- Understood and mitigated on earlier silicon cells

- Effect observed on SOA multi-junction (MJ) cells, cause not yet identified

- Cell-to-cell variation

- LILT Effect can be mitigated:

- Cell screening, optimization or advanced concentrator technology

- On-going advances in cell technology can provide improvements

- NASA will need to adapt those to LILT conditions 


\section{LILT Effect Mitigation}

Cell Screening

- Successful on Dawn

- In progress for Juno
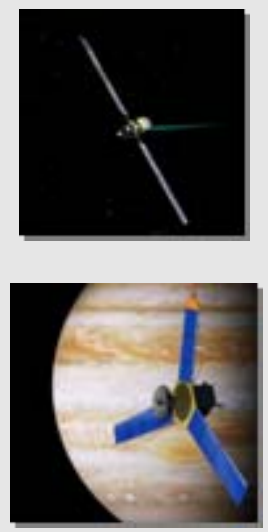

- GRC and Juno data indicate that effect worsens in frequency and magnitude with lowering intensity
Cell Optimization

- Silicon cells designed for LILT on Rosetta

- $5.2 \mathrm{AU},-130^{\circ} \mathrm{C}$

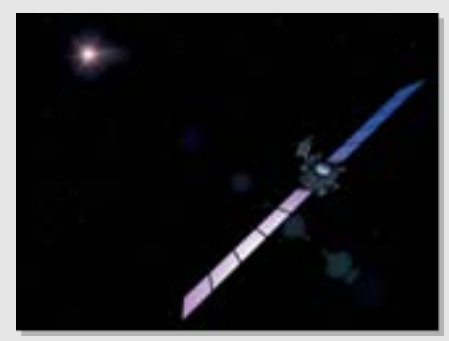

- Future cells could be optimized

- To eliminate LILT Effect

- To optimize cell performance and mass for LILT conditions
Concentration

- Maintains intensity

- Minimizes LILT Effect

- Reduces cell count

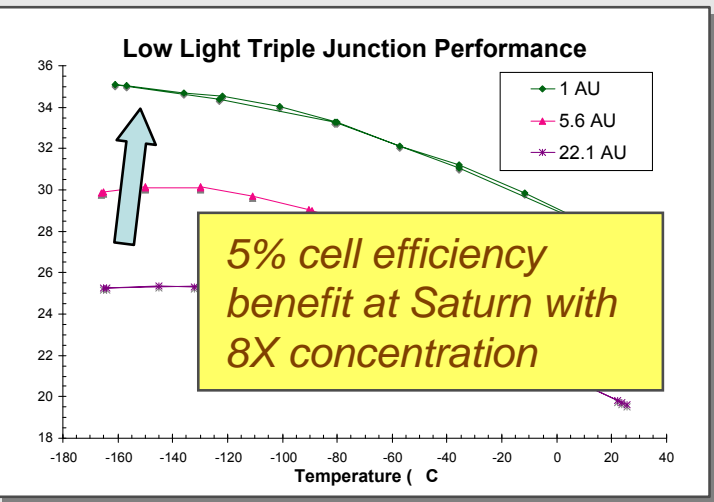

- Increased spacecraft system effects (pointing requirements) 


\section{Array Technology Findings}

\section{Advanced Solar Array Technology}

- Multiple technical paths exist to extend photovoltaic power use towards the outer solar system

- UltraFlex

- Near-term, high maturity

- Baseline for Orion power

- TRL6 by 2009 with subsequent qualification

- SquareRigger

- Mass competitive at large power levels

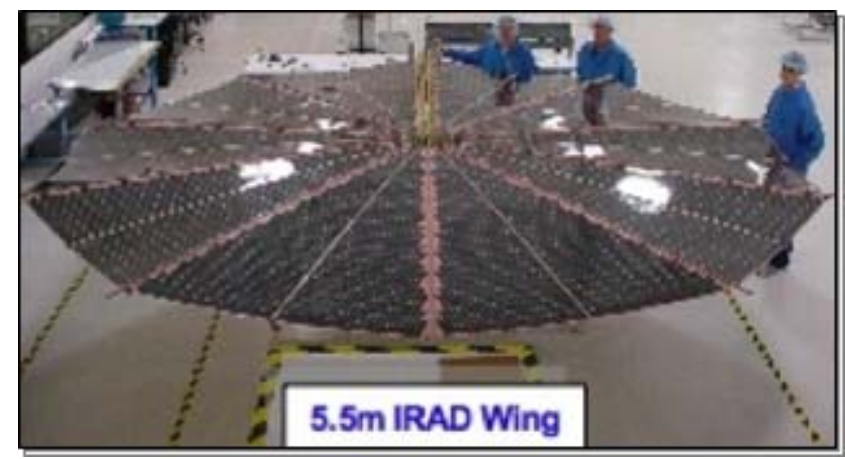

UltraFlex Wing

- Rectangular bays offer better scaling characteristics

- Compatible with planar and concentrator designs

- Stretched Lens Array SquareRigger (SLASR)

- Incorporates lightweight linear refractive concentrator derived from Deep Space 1 SCARLET

- SLA component flight demonstration on TACSAT-4

- Can scale to very high power levels

- Technology development is required:

- To extend UltraFlex diameter beyond state-of-art size

- To complete SquareRigger development at the array level

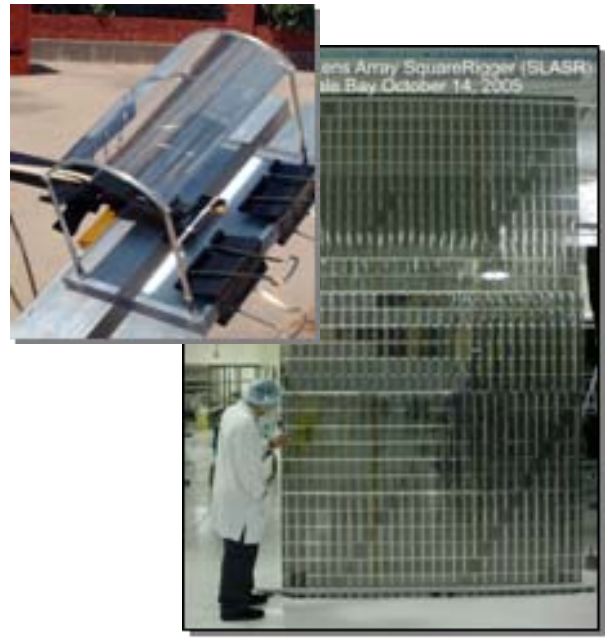

SLASR Bay

$2.5 \times 5 \mathrm{~m}$ 


\section{Mission Applications}

- A range of missions were considered to encompass power system sizing and spacecraft integration drivers, including:

- Heliocentric distance: 5 - 20 AU

- Operations concept \& power management: moon orbiters

- Radiation: Jovian moon orbiter

- Simplest missions: flybys

- Flagship-class

- Saturn Orbiter, Titan Orbiter

- Uranus Orbiter

- Ganymede or Europa Orbiter

- Pl-led

- Saturn Flyby

- Centaur Flyby or Rendezvous

- Saturn Orbiter analyzed in COMPASS team study

- Used NASA GSFC Enceladus architecture option Saturn-OL as reference

- Europa, Centaur and Uranus missions assessed analytically

- Representative point analyses performed with selected mission power 


\section{System Integration Considerations}

- Mass impacts of carrying the solar array into deep space

- Additional/larger systems: solar array, batteries, power conditioning systems, pointing systems (larger reaction wheels)

- Heavier thermal systems (lack of RPS waste heat)

- Structures/mechanisms to attach the solar arrays (impact from capture propulsion system)

- Net impact is reduced payload compared to RPS systems

\section{- Launch vehicle integration}

- Volume constraints in packaging stowed arrays

- Spacecraft integration and operations in mission orbit

- Multiple subsystem requirements for pointing and slew

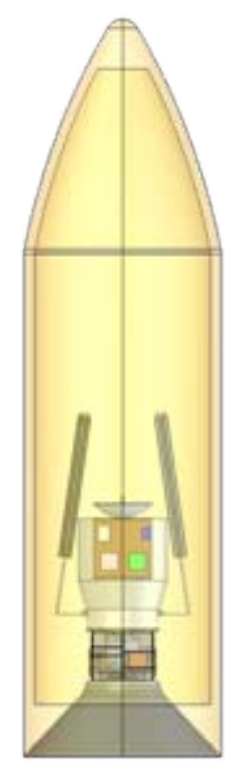

- Possible incompatibilities with science objectives

- Power system design

- Maintaining power through eclipse periods

- Radiation tolerant design

- Managing power in inner solar system, when generated power from array can be 10's - 100's of kW

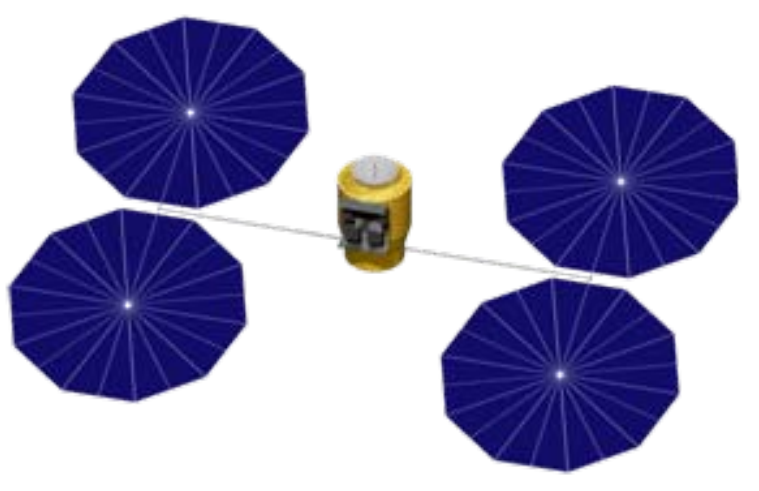




\section{Example: Saturn Orbiter Mission}

- Mission assumptions:

- Titan/Enceladus cycling orbit

- 335 W continuous nominal power (per Enceladus study)

- 11.5 yr VVEEGA voyage to Saturn

- Saturn and rings eclipse periods

- Total radiation degradation of 15\%

- Power system design options

- SOA cells/array:

- Nine SLASR bays at $237 \mathrm{~kg}$

- Twelve Planar Squarerigger bays at $470 \mathrm{~kg}$

- Four, 7.2 m diameter Ultraflex arrays at $415 \mathrm{~kg}$

- Projected cells/array:

- Eight SLASR bays at $205 \mathrm{~kg}$

- Ten Planar Squarerigger bays at $321 \mathrm{~kg}$

- Four, $6.7 \mathrm{~m}$ diameter Ultraflex arrays at $268 \mathrm{~kg}$

- System-level drivers

- COMPASS study performed to assess system drivers, details follow

- Technology feasibility

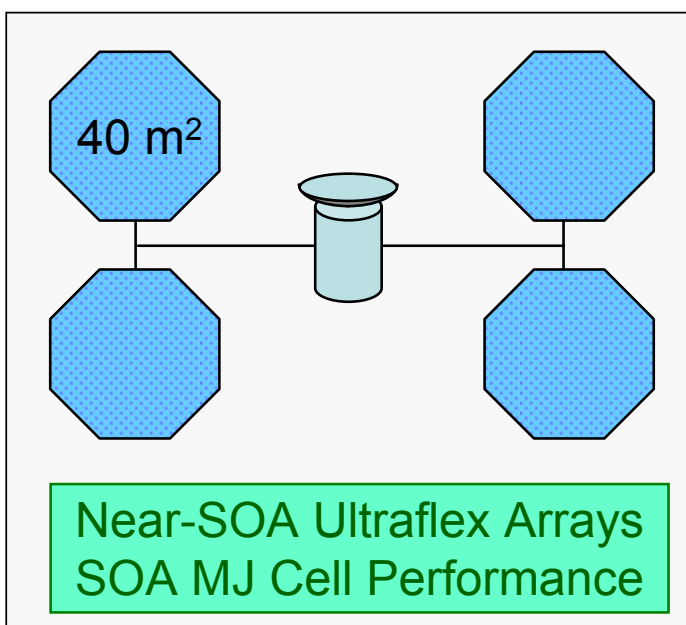

$48 \mathrm{~kW}$ BOL at $1 \mathrm{AU}$

Interplanetary voyage

$377 \mathrm{~W}$ at Saturn arrival

- Planetary radiation

- Energy storage for eclipse periods

$335 \mathrm{~W}$ EOL power

- Target power level can be achieved with near-term PV technology 


\section{Solar Saturn Probe Design Study}

- Reference ASRG-powered spacecraft

- Power: 335 W

- 3 ASRGs

- Science payload: -1000 kg, includes lander

\section{- Solar-powered spacecraft}

- $48 \mathrm{~kW}$ solar arrays at $1 A U$

- Science payload: $\sim 550 \mathrm{~kg}$

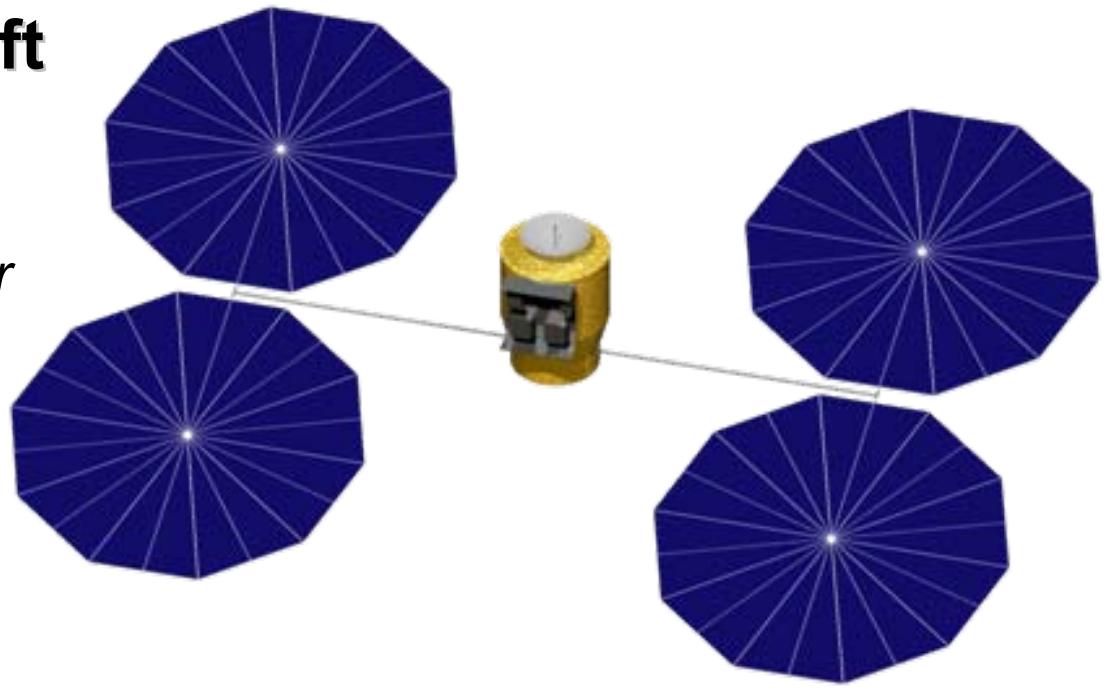

\begin{tabular}{|l|c|l|}
\hline $\begin{array}{c}\text { Solar Powered } \\
\text { Subsystem }\end{array}$ & $\begin{array}{c}\text { Mass Change Compared } \\
\text { to RPS probe }\end{array}$ & \multicolumn{1}{|c|}{ Cause } \\
\hline Payload & $-450 \mathrm{~kg}$ & Increase in bus subsystems mass \\
\hline Power & $+340 \mathrm{~kg}$ & Solar arrays, mechanisms, PMAD \\
\hline ACS & $+30 \mathrm{~kg}$ & Heavier wheels (ACS propellant increased) \\
\hline C\&DH/Comm & $+15 \mathrm{~kg}$ & Increase in pointing, more complex spacecraft operations \\
\hline Thermal & $+30 \mathrm{~kg}$ & Additional blankets, heaters, RHUs due to lack of waste heat for RPS \\
\hline Structures & $+30 \mathrm{~kg}$ & Solar array booms \\
\hline
\end{tabular}




\section{Other Power System Sizing Results}

- Mission integration factors not considered

- Implementation may not be feasible

- Echeclus

- Arrival in 2019 @ 9 AU

- $300 \mathrm{~W}$

- 4 SOA 5.5m Ultraflex wings with SOA MJ cells

- Chiron

- Arrival in $2028 @ 18$ AU

- $200 \mathrm{~W}$

- 16 SLASR bays $\left(200 \mathrm{~m}^{2}\right)$ with projected MJ cells

- Europa Orbiter

- Jovian tour, ending in $100 \mathrm{~km}$ altitude orbit

- $720 \mathrm{~W}$

- 8 SLASR bays $\left(100 \mathrm{~m}^{2}\right)$ with SOA MJ cells

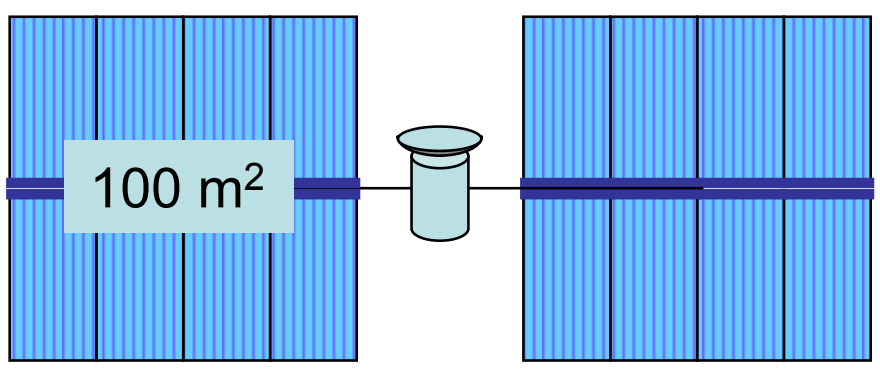

Notional array size
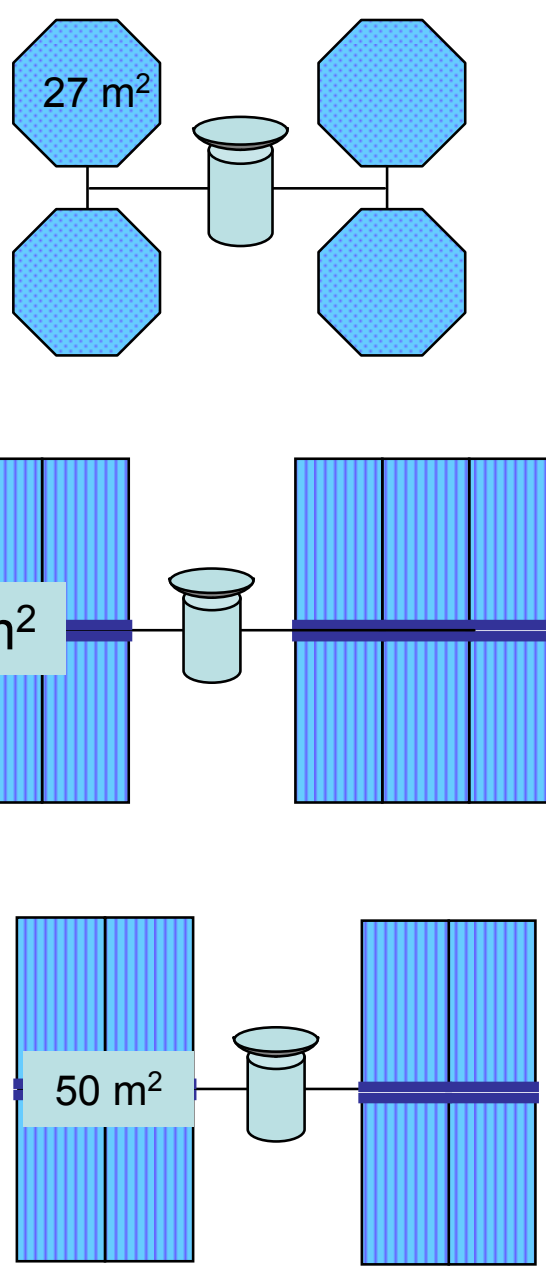


\section{Technology Leverage Summary}

\section{Power improvements achievable through technology investment}

Power at Saturn:

- Interplanetary-only (no eclipses, planetary radiation)

- Fixed mass power system
Key Technology: Lightweight Arrays $+80 \%$ Power

\section{SLASR/SOA Cells}

$360 \mathrm{~W}, 233 \mathrm{~kg}$,

9 bays $(2.5 \mathrm{~m} \times 5 \mathrm{~m})$
Key Technology: Cell Improvements $+5 \%$ eff., lower mass $+58 \%$ Power $200 \mathrm{~W}, 233 \mathrm{~kg}$, 4 wings, $5.4 \mathrm{~m}$ diameter SLASR/ Projected Cells $420 \mathrm{~W}, 233 \mathrm{~kg}$, 9 bays $(2.5 \mathrm{~m} \times 5 \mathrm{~m})$

\section{Underlying Development and Technologies}

- Qualify UltraFlex for low temperature application

- LILT Effect Evaluation for MJ Cells

- Blanket Technologies for Low Temperature Conditions 


\section{Conclusions}

- Near-term arrays and SOA multi-junction cells may provide capability to perform low power (200-300 W) missions out to $10 \mathrm{AU}$

- Further investigation of LILT Effect is warranted if PV power is to be considered for more demanding outer planet missions

- LILT Effect can be mitigated through multiple approaches

- Advanced cell and array technologies would extend the practical application of PV power through mass and efficiency benefits

- Clear technology paths exist to enhance PV application to outer planet missions

- Implementation of PV power will decrease payload mass

- Feasibility of PV use critically depends on mission and spacecraft concept

- NASA continues to push PV use outward in the solar system 